\title{
Uluslararası Sanat Müziğinde Beste ve Starvinsky'nin Besteleme Edimi Üzerine Düşünceleri
}

\section{Composition in International Western Art Music and The Thoughts of Starvinsky on Composition}

\author{
Barış Erdala,* Q id
}

aSivas Cumhuriyet Üniversitesi Eğitim Fakültesi Güzel Sanatlar Eğitimi Bölümü Müzik Öğretmenliği Programı

Article history: Received 09-11-2019 / Accepted 28-12-2019

\section{ÖZET}

Müziğin oluşması için en temel boyutlardan biri icra ise, diğer ve daha önemli bir boyutu yaratılmasıdır denebilir. Bugün müziğin farklı kültürlerde, kültürel yapının niteliğine göre çok çeşitli üretim biçimlerine sahip olduğu bilinmektedir. Dünya üzerinde var olan diğer birçok kültürden (üstün değil) ayrı olarak, Avrupa medeniyetinin Antik Yunan'a dayanan ses sistemi, yüzyıllar içinde evrimleşerek sistematik bir bütünselliğe kavuşmuştur. Bu gelişmeler uzantısında batı sanat müziğinde beste ve bestecilik kavramları ilk defa 15. ve 16. yüzyıllar arasında ortaya çıkmıştır. Günümüze kadar Türkçeye çevrilen ya da Türkçe yayınlanan birçok kaynakta, besteleme edimine birkaç sözlük maddesi dışında pek yer verilmemiştir. Dolayısıyla ünlü besteci Starvinsky'nin besteleme edimi üzerine düşüncelerini de içeren bu çalışma, belirli bir çerçevede bu ihtiyacı karşılamayı amaçlamıştır. Ulaşılan sonuçta, batı sanat müziğinin besteleme edimiyle geleneksel ve popüler müziğin üretilmesi arasındaki farkların belirginleştirilmesi üzerine odaklanılmıştır.

Anahtar Kelimeler: Uluslararası Sanat Müziği, Beste, Besteci, Geleneksel ve Popüler müzik.

\section{ABSTRACT}

If one of the most fundamental dimensions for the formation of music is the execution, it can be said that creation is another and more important dimension. Today in different cultures, it is known that music has a wide variety of production styles which can be changeable by the nature of the cultural structure. Apart from many other cultures (not superior) that exist on Earth, the European civilization's sound system, which was based on Ancient Greece, had evolved over the centuries and had achieved a systematic unity. As a result of these developments, the concepts of composition and composer in western art music first appeared between the 15th and 16th centuries. Many sources, which have been translated into Turkish or published in Turkish, have not included the act of composing, except for a few glossary articles it. Therefore, this study, which included the thoughts of the famous composer Starvinsky on the act of composition, aims to meet this need within a certain framework. At the end of discussion of related literature the difference between the ways in which Western art music and traditional and popular music were created was delineated.

Keywords: Western Art Music, Composition, Composer, Traditional and Popular music.

\section{GİRİŞ}

Farklı coğrafya ve kültürlerde farklı toplumsal bilinç düzeylerinin yansıması olduğu kadar özel bir üretim tarzını da ifade eden sanat, var olagelmiş türleriyle insanın kendini ifade etme isteğini, dahası, bu ifade edebileceği tarzları bulmak için gösterdiği çabayı yansıtır. Başlangıcı ister topluluk ritüellerinin bir parçası olsun, ister üstün bir zanaatçının yarattığı ürünler olsun, insan doğasının gereksinimleriyle eşzamanlı gelişmiş Avrupa Rönesans dönemiyle birlikte kavramsal bir boyut kazanmıştır. Yunanca tekhne (teknik-el sanatı) ve Latince ars (sanat) terimlerinden türeyen kavram, Ortaçağ süresince zanaattan ayrı düşünülmese de Avrupa sanayi devriminden sonra net olarak zanaattan ayrı ele alınmaya başlamıştır. Bu gelişim çizgisi içinde beste ve bestecilik kavramları ilk kez Rönesans'ın ışığında ortaya çıkmıştır.

İfade kültüründe yaratım biçimlerinden birisi olarak müzik, daha dar anlamda ise müzik türleri üç genel kategoride değerlendirilebilir. Dünya üzerinde bütün toplumlarda görülebilecek geleneksel (traditional) ya da halk (folk) müziği, göreli olmakla birlikte geniş 
kitlelere hitap eden popüler (popular) müzik ve üretimi yoğun bir entelektüel çaba gerektiren sanat (art) müziği. İster halk ister geleneksel, isterse popüler ya da sanat müziği olsun, bütün müzik türleri bir yaratıcı/lar tarafından üretilir ve bu üretimin sonucu müziksel yaratı olarak adlandırılır. Bu çalışmada genel çerçeve uluslar arası batı sanat müziği (western art music) ile sınırlı tutularak, müziksel yaratımın ve yaratıclığın karşılığı olarak kullandığımız beste (composition) ve besteci (composer) kavramları belirli boyutlarıyla irdelenmiştir. Kavramların geleneksel ve popüler müzikte kazandığı anlamlar, farklılıklar kapsamında çözümlenmeye çalışılmıştır.

\section{MATERYAL VE YÖNTEM}

Bu araştırma, nitel araştırma yöntemlerinden literatür tarama metodu ile gerçekleştirilmiştir. Çalışmada konuya yönelik ulaşılabilen online ya da basılmış bilimsel yayınlar ve ilgili kitaplar taranmış, analitik bir yaklaşımla kavramsal çözümlemeler yapılmaya çalışılmıştır.

\section{BESTE KAVRAMININ ORTAYA ÇIKIŞI VE GELİ̧̧ímí}

Avrupa bilim ve sanat tarihinde günümüze değin yaşanan birçok gelişme, Orta çağın sonu ile Yeni Çağ'ın başlangıcı arasında bir köprü olan Rönesans (yeniden doğuş) hareketiyle ilişkilendirilir. Yaklaşık 15. yüzyıın ilk çeyreğinden 16. yüzyılın ortalarına kadar uzanan bu süreç, bilim-teknoloji ve sanat alanlarında köklü değişimlere zemin olmuştur. Dönem içerisinde Avrupa çoksesli sanat müziğinin geçirdiği ve sonraki yüzyılları şekillendirecek çok yönlü evrimi birkaç nedene bağlayarak açıklamak mümkün olmayabilir. Ancak ortaya çıkan sonuçlar itibariyle, hem sanat müziğinin hem beste kavramının genel hatlarını irdelemek olanaklı gözükmektedir.

Kaynaklardan anlaşıldığına göre kıta ülkelerinde çoksesliliğin ilk örnekleri paralel iki ezginin dörtlü, beşli ve sekizli aralıklarla icra edilmesine karşılık gelen organum'lardır ancak bu çokseslilik Gregor ezgileri üzerine kurulur. "Kaynağı Ortadoğu - genellikle İbrani - Grek ve Roma makamlarına dayalı kilisenin törensel musikisine, halk katında ortaya çıkan daha özgürce biçimlenen ezgilerin etkimesi karşısında Papa Gregor, kilise törenlerinde, tüm Hıristiyan dünyasında birlik sağlamak amacıyla kendi adıyla anılan ezgileri saptar" (Fırat, 1999: 41). Yaklaşık M.S. 900 ve 1200 yılları arasında yaşanan organum dönemi, çok sonraları ezgiye karşı ezgi anlamına gelen contrapunt'un yani polifonik yapının temelini oluşturacaktır.

Avrupa sanat tarihinde kilise etkisinin yüzyıllar geçtikçe güç kaybetmesinde peşi sıra ortaya çıkan akımların rolü her zaman görülebilir. 12. yüzyıla doğru Fransa'da ortaya çıkan gezgin ozanların (troubadour-trouvéré) ardından birbirine karşıt gelişen iki akım çokseslilik araştırmalarının gelişmesiyle birlikte kilise müziğini derinden etkilemiştir. Çoksesli müziğin gelişim sürecinde milat olarak kabul edilebilecek Ars Antiqua (eski sanat, yaklaşık 11901315) ve Ars Nova (yeni sanat, yaklaşık 1315-1410) akımları Rönesans'a giden yolda önemli uğraklardır. Ars Antiqua müzik teorisyenlerinin süre gösteren notaları kullanmaya başlamakla müziğe ölçü sistemini yerleştirmeleri, dönem atmosferinde tercih edilen yeni türlerde (zamanla kilisenin de kabul etmek zorunda kalacağı) üçlü aralığın kullanımının kesinlik kazanması, dahası A-B-C öğelerinden meydana gelen bir form anlayışının geliştirilmesi çok sesli müzikte yaşanan ilk devrimci atılımlardır. Ars Nova ise, Ars Antiqua'nın buluşlarını daha ileri bir aşamaya taşımıştır. Besteciler bir önceki kuşağın alışkanlıklarından uzaklaşarak motet ve chanson gibi yeni türlere yönelmişlerdir. Dolayısıyla bu yeni arayışlar, çok tutarlı olamamakla birlikte notasyon üzerinde yapılan deneysel çalışmalar ve özellikle daha sınırlanmış bir ritmik dile ulaşma çabası kullanılan nota değerlerinin küçük değerlere bölünmesiyle sonuçlanmıştır. Böylece Rönesans'a kadar hem ölçülü nota sisteminin gelişmesi hem yeni aralıkların müziğe dahil edilmesi müzisyenlerin hareket alanını oldukça genişletmiştir.

Batı kültüründe müzisyenlerin, özellikle teoriysen ve bestecilerin müziği tanımlama çabası içine girmeleri Rönesans'la birlikte belirginleşir. Nitekim beste kavramını ilk olarak bu dönemde görüyoruz. Terim Latince Res Facta "yapma bir şey" anlamıyla ilk kez Johannes Tinctoris tarafından kullanılmıştır. Tinctoris 1472 'de yazdığı Terminorum Musica Diffinitorium adlı teori kitabında beste kavramını cantus compositus kavramıyla aynı anlamda ele alır. Genel olarak bir partdaki notaların diğer partlarla çok yönlü bir ilişki içerisinde ezgilenmesine Res Facta denir. Res Facta'nın asıl çıkış noktası ise 'ezgiye karşı ezgi' ya da çağdaş 
bestecilerimizden Ertuğrul Oğuz Fırat'ın girdili diye nitelediği kontrpuandır. Kökeni organuma kadar uzanan bu sitil yoğunlukla motet, missa gibi türlerde tenor partisiyle oluşturulur. Curt Sachs'a göre; "Tenorun görevi hiçbir zaman belirli bir ezgi değil, üst seslerin dokusuna sağlam bir dayanak olabilecek eşit süreli, düzgün, temel taşı görevi görmektir. Bir motet'in tenor sesi ya bir çalgıya, ya da sözsüz bir sese bırakılmıştır. Bu partinin sözleri yoktu ama incipit 1eri, yani ezginin aldığı dinsel şarkının ilk sözü ya da sözleri vardı. Bu parti üç notalık bir ezgiyle ardından bir sus gelerek yapılmak zorundaydı. Bu ezgi, bazen de dört notalık ezgiciklerin bütün motet boyunca sürmesiyle de yapılırdı. Bazı durumlarda motet'in bütününü değil, yarısını ya da üçte birini kaplıyordu" (Say, 1995: 93).

E. O. Fırat aynı tenordan contra partisi olarak söz eder. "Rönesans'ın ilk dönemlerinde çok sesli yapıtlar genellikle üç ses için yazılırdı. Tizde ve petse iki ezgisel çizgi arasında, ezgi dışı sık sık atlayışlar gösteren contra denen üçüncü bir parti daha bulunurdu. Contra partisi uyumsal dokuyu kurmak amacını güderek büyük sıçramalar gösterebilen ezgi dışı bir parti olduğundan genellikle çalgılarla çalınırdı" (Fırat, 1999: 66).

Tinctoris'in ikinci kitabı (1477) Liber de Arte Contrapuncti bu sanatın inceliklerini anlatır. "Hem basit hem eksiltilmiş kontrpuan iki şekilde yapılır. Yazarak ya da zihinsel (doğaçlama) çalışmayla. Yazılı kontrpuana genellikle Res Facta denir. Ancak kontrpuan bazı yönleriyle Res Facta'dan ayrıır. Kontrpuanda partlar arasındaki ilişki her bir sesle tenor arasındadır. Res Facta'da ise bütün partların her birisi birbirleriyle ilişkilidir" (Grove music, 2005). E. T. Ferand, Tinctoris'in bu iki tanımlamasında ortaya çıkan muğlâklığı ve çelişkiyi iki biçimde aşmayı önerir. Ona göre Tinctoris'in, ya kontrpuan ve beste kavramları arasında koyduğu ayrım inmal edilmeli, ya da Res Facta'nın yazılı kontrpuana eşit olduğuna dair genel görüşü tamamen kabul etmediği düşünülmelidir. Ferand kontrpuanın yazılı olma niteliğini temel alır. Yazılı kontrpuantal beste Tinctoris'e bağlı olarak düşünüldüğü biçimiyle basit ya da doğaçlama kontrpuanla karşılaştırılabilir bir ilişkiye sahiptir. Dolayısıyla yazılı kontrpuan doğaçlama kontrpuandan ayrılır. Tinctoris'in tanımları üzerine yapılan yorumlar farklılaşmakla birlikte, kontrpuanın süregelen ikili anlamının altında ister yazılı ister doğaçlama olsun, temelde çok partı besteleme yatar. Bu noktada, nasıl bir düz yazı, altında yatan gramer yapılarına ayrıştırılabiliyorsa yeri geldiğinde kontrpuantal bir bestenin de altında yatan kontrpuana indirgenebileceğini düşünmek yol gösterici olabilir.

Kompozisyon (beste) kelimesi "Latince componare'den gelir ve (put together) bir araya getirme anlamındadır. Etimolojik olarak öncelikli anlamları, bestelenmiş olma durumu ya da besteleme eylemine işaret eder. Başka bir yaratım sürecini ifade eden yorum (interpretation) ve doğaçlama (improvisation) performans sırasında ortaya çıkmalarıyla besteden ayrılır" (Grove music, 2005). Etimolojik olarak aynı zamanda "tümleme, bir araya getirme, derleme, tertip, terkip, nitelik, bileşim, alaşım, uzlaşma, anlaşma" anlamlarında kullanılabilmektedir (Yavaşça, 2002: 1).

\section{ULUSLARARASI BATI SANAT MÜZİĞİNDE BESTE}

Hangi müzik türünde olursa olsun herhangi bir yaratım süreci incelemesinin oldukça güç olduğu söylenebilir. Bu bölümde uluslar arası sanat müziğinde besteleme edimini oluşturan belirli noktalar anlaşılmaya çalışılacaktır.

Avrupa çok sesli sanat müziğinin günümüze kadar geçirdiği evrimlerde, bestecilerin kendine özgü bir bütün (beste-kompozisyon) oluşturmada müziğin dört ana unsurunu kullandığı söylenebilir. Bu temel yapı taşları ritm, ezgi, armoni ve biçim-form olarak sıralanabilir. Kullanılan bu dört unsurun temeli ise ses ve zaman'in sınırsız olasılıklar içinde oluşturulan bireşimleri ile ilişkilidir.

Diğer yandan bir kompozisyonun yaratım sürecinde yazılı hiçbir kural yoktur denebilir. Ancak genel bir yaklaşımla hangi müzik türünde ve biçiminde olursa olsun bazı yöntemlerden, tekniklerden, geleneksel ya da yeni yaklaşımların varlığından söz etmek mümkündür. Sonuçta beste yapmak için üç temel öğeye ihtiyaç vardır. Bunlar "ses, sesleri düzenleme ilkeleri, yaratıcı düşünce ve buluş" olarak üç ana başlıkta toplanmaktadır. (Say, 2005)

Müzik için ses zorunlu bir ham maddeyse, sesin süresi, gürlüğü, rengi ve yüksekliği gibi unsurlar besteci için temel malzemelerdir. Bunula birlikte sesleri düzenleme ilkeleri, bir kompozisyonun oluşma sürecinde bestecinin kullandığı bir takım yöntem ve tekniklere işaret 
eder. Hemen hemen birçok müzik türünde görebileceğimiz çeşitleme, tekrarlama, taklit, çevrim vb. teknikler bestecinin ulaşmak istediği bütünselliğin şekillenmesinde belirli işlevleri yerine getirirler. Dolayısıyla bu tekniklerin kullanımı (ki bir beste rastgele birleştirilen sesler topluluğu olmadığına göre), bütünü oluşturan her bir parçanın belirli estetik ilkelere göre düzenlenmesini zorunlu kılar. Denge, karşıtıklar, mantıksal bir bütünsellik bu estetik yordamların başlıcalarıdır. Doğal olarak, yukarıda verilen bütün bu elementlerin birleşiminden oluşan bir eserin ruh ve karakter kazanması bestecinin yaratıcılığına bağlıdır. Buluşsal yaratıcılık her yönüyle besteleme ediminin merkezine oturur.

Çoğu insan sanat ya da müzik üretimini harekete geçiren unsurların başında, sanatçının hayal gücünü canlandıran ve yönlendiren ilham'ın varlığını birincil etken olarak düşünür. Üretim sürecinde zihinsel eylemlerini açıklamaları istenen bestecilerin geneli ilhamın varlığını kabul etmekte birleşirken, ilhamın belirdiği anda gelişen fikirlerin değerlendirilmesi için çok çalışılması gereğinden bahsetmişlerdir. Bazı besteciler ilhamın çalışmayla geliştirilen bir motif ya da tema olduğunu söylerken, bazıları kendilerini müzik yoluyla ifadeye zorlayan güçlü ve değişik bir duygusal mod olduğunu söylemiştir. Örneğin "Cesar Frank kompozisyonu önce bir modülasyon planı olarak tasarlayıp sonra işlediğini söylerken; Ravel ikinci keman sonatında, motif ve temaları düşünmekten çok daha önce, zihninde temaların özelliklerine göre düzenleyeceği çalgısal yapıyı biçimlendirdiğini" ifade etmiştir (Say, 1984: 730).

İlerleyen sayfalarda Stravinsky'nin ifade ettiği gibi, uzun ya da kısa bir eserin ortaya çıkması aslında birçok sınırlamayla ilişkilidir denebilir. Batı sanat müziği tarihindeki kompozisyonlara bakılırsa, büyük bir kısmının tema veya bu temaları oluşturan daha küçük motiflerden türediği görülür. Tek yönlü bir bakış açısıyla müzikal motiflerin-temaların kendiliğinden oluşmasına ilham denirse, ilhamın herhangi bir zaman diliminde ortaya çıkabileceğini düşünmek mümkündür. Bu bağlamda Mozart, "Fikirlerimin en iyi ve en bol geldiği sıralar, tamamıyla kendim olduğum, tam anlamıyla yalnız ve mutlu olduğum zamanlardır. Bir arabada giderken, iyi bir yemekten sonra yürüyüş yaparken veya uyumadığım bir gece olabilir bu. Müzik fikirlerimin ne zaman ve nasıl geldiklerini bilmiyorum, ortaya çıkmaları için de zorlamam mümkün değil. Onları hafızamda tutar ve mırıldanırım. Buna devam ettiğimde, şu veya bu parçayı nasıl değerlendirip iyi bir bütün haline getirebileceğimi kavrarım" demiştir (Say, 1984: 730).

Diğer yandan Stravinsky için ilham yaratma ediminin önkoşulu değildir, ilham ancak ikinci sırada bir öneme sahip olabilir. O her yaratımın kökeninde, keşfin önceden tadına varılmasının ortaya çıkardığı bir tür iştahı varsayar. Yaratma edimindeki bu önceden alınan tat, ele geçirilmiş olmasına rağmen henüz anlaşılmayan, bilinmeyen bir varlığın kavranışına eşlik etmektedir. "İlham, sanat, sanatçı gibi birçok -en azından puslu- sözcük, içinde spekülatif ruhun soluk aldığı, her şeyin denge ve hesap işi olduğu bir alanı açık seçik görmemizi engeller. İlhamın kökünde bulunan coşkusal rahatsızlık ancak daha sonra ortaya çıkabilir. Bu coşkunun henüz yaratma ediminin nesnesi olan, sonradan sanat eseri olacak o bilinmeyen varlığın hakkından gelmeye çalışan yaratıcının bir tepkisi olduğu açık değil mi? Dikkatimi çeken müzikal öğeleri düzenleme düşüncesinin bile bende uyandırmaya yettiği bu iştah, ilham gibi rastlantıya bağlı bir şey değil, sürekli olmasa da doğal bir ihtiyaç kadar alışılmış ve periyodik bir şeydir" (Stravinsky, 1942: 41).

Yukarıda paylaşılan düşüncelerin tersine ilhamı yadsıyan besteciler de vardır. İtalyan besteci Aflredo Casella, "en kusursuz oldukları genellikle kabul edilen bestelerimi yaparken, ortada duygunun hiç olmadığını söyleyebilirim. Sanatsal yaratıcılık için şüphesiz en iyi durum (konuyla ilgili olmayanların az çok ilahi bir heyecan durumu olduğunu farz ettikleri hal), beyin faaliyetlerinin son derece berrak olmasıdır" demiştir. Benzer şekilde Richard Strauss beste yaparken sakinliğin önemine dikkat çeker. "Çok sakin, sıkıntısız ve hatta duygusuzluk içinde çalışırım. O değişken, hareketli, akıcı, karmaşık orkestrasyonu yönlendirmek için, kişinin kendine tamamen egemen olması gerekir. Herhalde Tristan'ı bestelemiş olan zihin bir mermer kadar soğuktu" (Say, 1984: 732).

İlham üzerine farklılaşan bu yaklaşımlar dışında, müzik üretimi için müziksel fikirlerin bulunması bestecinin her zaman en büyük sorunu değildir. Bu fikirlerin elenip seçilmesi daha önemlidir. "Bütün sanat bir seçme işini varsayar. Çoğu zaman çalışmaya başladığımda hedefim henüz kesinleşmemiştir. Yaratım sürecinin bu evresinde ne istediğim sorulursa, 
söyleyecek pek bir şey bulamam. Ama ne istemediğim sorulursa, her zaman kesin bir cevap verebilirim. Eleyerek ilerlemek, kumarda dendiği gibi neyi elinden atacağını bilmek: Büyük seçim tekniği işte budur. Burada gene çokun içinde birin aranmasını görüyoruz" (Stravinsky, 1942: 52).

Seçmek için elemek, birleştirmek için de çeşitlendirmenin zorunluluğuna vurgu yapan Stravinsky besteleme sürecinde ele alınan öğeleri elekten geçirirken aynı zamanda insan etkinliğinin kendi üzerine sınırlamaları olması gerektiğini savunuyor. Ona göre sanat ne kadar kontrol edilir, sınırlanır, üzerinde çalışılırsa, o kadar özgür olur. "Kuramsal bir özgürlük karşısında elimden bir şey gelmez. Sonlu, belirli bir şey verin bana; yalnızca sahip olduğum olanaklar ölçüsünde müdahalelerime cevap verecek bir malzeme verin. Böyle bir malzeme bana kendini sınırlılıklarıyla birlikte sunar. Bende ona ister istemez sınırlılıklarımı yüklerim. Hoşumuza gitse de gitmese de burada zorunluluklar dünyasındayız. Şimdiye kadar hangimiz sanatın bir özgürlük dünyasından başka bir şey olduğunun söylendiğini duyduk. Başka her şeyde olduğu gibi sanatta da ancak dirençli bir temel üzerine bina kurulabilir. Etkinlik alanımı ne kadar sınırlarsam ve kendimi ne kadar çok engelle kuşatırsam, özgürlüğüm de o kadar büyük ve anlamlı olacaktır. Sınırlamayı azaltan gücü de azaltır. İnsan kendini ne kadar kısıtlarsa, ruhuna pranga vuran zincirlerden de kendini o kadar kurtarabilir" (Stravinsky, 1942: 51).

Sözü edilen bu sınırlılıklar içerisinde gerçekleştirilen seçim ya da seçimler, yaratım sürecine egemen olan iki temel kavramla ilişkilidir. Çeşitlilik ve Birlik. Stranvinsky bütün sanat türlerinde bu iki temel ilkenin görülebileceğini, kendisi için bu iki ilke arasında benzerliklerle ilerlemenin zıtlıklarla ilerlemekten genellikle daha doyurucu olduğunu söylüyor. Başka bir deyişle, çeşitlilik ve birlik kavramlarının zorunlu diyalektik bağı, seçim aşamasında değerler hiyerarşisinin önemine işaret ediyor. "Çeşitlilik, ancak benzerliğe ulaşmanın bir aracı olarak geçerlidir. Her tarafta çeşitlilik görürüm. Öyleyse ondan yoksun kalacağım diye korkmama gerek yok çünkü hep onunla karşı karşıyayım. Zıtlık her yerdedir. İnsanın yalnızca dikkat etmesi yeter. Benzerlik ise saklıdır; aranması gerekir ve ancak etraflı çabalarla bulunabilir. Çeşitlilik beni baştan çıkardığı zaman, sunduğu kolay çözümlerden rahatsızlık duyarım. Öte yandan benzerlik daha güç sorunlar ortaya çıkarmakla birlikte, aynı zamanda ve dolayısıyla benim için daha değerli sonuçlar sunar" (Stravinsky, 1942: 31).

Stranvinsky yukarıda anlatılanların uzantısında kendisi için beste yapmanın, piyanodaki ses skalası içinden belli sayıda sesi belli aralık ilişkilerine göre düzenlemek olduğunu söyleyerek genel bir tanıma ulaşıyor. "Bu etkinlik beni, giriştiğim işin içerdiği ses dizisinin üzerinde birleşeceği merkezi araştırmaya götürür. Böylece, eğer bir merkez verilmişse, bunun üzerinde birleşecek bir bileşim bulmak zorunda olurum. Öte yandan, eğer henüz hiçbir yere yönelmemiş bir bileşim bulmuşsam, bunun gideceği merkezi saptamak zorunda olurum. Bu merkezi keşfetmem, bana sorunun çözümünü telkin eder. Böylelikle, bu tür bir müzikal topografyaya duyduğum büyük ilgiyi tatmin ederim" (Stravinsky, 1942: 34).

\section{BİçíM-FORM}

Bir bestenin oluşum sürecinde kullanılan materyallerin bireşim yeri diyebileceğimiz biçimform, sanatsal yaratının kemiğe büründüğü alan olarak tanımlanabilir. Doğada bulunan her varlığın nasıl bir biçimi varsa, yüzyıllar boyunca güzel sanatlar da kendine özgü biçimler yaratarak gelişmiştir (Erdal, 2003). "Sanatsal biçim, sanatsal içeriğin dolayımsız varlık ve düzenleme biçimi olduğu kadar, tarihsel gelişme biçimidir de. Biçim aracılığıyla, sanatsal içerik, kendi varlığına kavuşmakla kalmaz aynı zamanda biçim yoluyla düzene de girerek kendine özgü yapısına kavuşur" (Çalışlar, 1991: 333). Alman besteci Hans Eisler'e (2006) göre müzik dilini ve düşüncelerini biçim içinde bulur, biçim olmaksızın ancak gevezelik edilir, konuşulamaz.

Bununla birlikte biçim kavramı aynı zamanda yapı kavramıyla ilişkilidir. Boris de Schloezer'e göre yapı, "değişik parçaların bir bütün meydana getirmek üzere çatılış yolu, biçim ise bir birlik olarak ele alınan bu bütünün ta kendisidir" (Hodeir, 1971: 5). Biçim ve yapı ilişkilendirildiği duruma, pozisyona bağlı olarak değişik anlamlara sahiptir. "Müziğin içindeki yapı ya da müziğin yapısı (biçimi). İlk kombinasyonda yapı çok geneldir. Müziğin karmaşık sesler topluluğu olmaması ve diğer bütün sanatlar gibi formül oluşturulabilen pek çok açık 
ilkelere göre düzenlenmesinden dolayı yapı müzik için gereklidir. En basit bir melodi bile farklı ses yüksekliklerine, belirli bir ritme ve cümlelere sahiptir. Bu da demektir ki melodi bir yapıya sahiptir. İkinci kombinasyona göre bestelenen eserin omurgasını oluşturan ve müzik tarihinin çeşitli dönemlerinde kullanılan füg, sonat gibi planlar belirli bir müzik biçimini tanımlar. Biçim ve yapı kavramlarının karmaşıklığı bir örnekle açıklığa kavuşturulabilir. Ses materyalini vücudun derisi ve hücreleri olarak düşünürsek, biçim materyalini bu bütünü tutan ve şekil veren bir destek olarak tanımlayabiliriz. İlki kemiklere ve kasa bağlı kompleks bir yapıyı oluşturur kompozisyon içindeki yapı. Diğeri de deri gibi dış yüzeyi oluşturur kompozisyonun yapısı (Apel, 1951: 277).

Uluslararası batı sanat müziğinde bir kompozisyonun ortaya çıkması için gerekli temel unsurlar (ritm, ezgi, armoni vb.) Hodeir'in tanımıyla, bir bina yapmak için gerekli kum, çimento ve tuğla gibi malzemelerin bulunup da, inşaatın ne şekilde nasıl bir planla çatılacağı sorunu ile benzerdir. "Bir müzik cümlesi ne denli güzel olursa olsun anlatımının en yüksek noktasına ancak dolayındakilerle tam bir uyuşum içinde olduğunda varır. Ne bir süreklilik, ne bir yapı, ne de bağlantılarında bir mantık olmayan, rast geleliğin ve keyfe göreliğin en düşüğüne bağlı bir eser nasıl bir eser olabilir?" (Hodeir, 1971: 6).

Müzik üretiminin gelişi güzellikten uzak bir süreç olması, müziksel düşüncelerin öne sürülmesinin ardında aslında bir takım düzenlilik kurallarının var olduğuna işaret eder. Bir müziksel düşüncenin ortaya konmasından ne anlaşılabilir? Yalın bir ifadeyle, müziksel bir düşüncenin notalar aracılığıyla verilmesi. Bu noktada bir iletişim söz konusu ise, insanın dildüşünce diyalektiğini ürettiği zamandan bu yana geçerli olan bir yasa karşımıza çıkar. Anlaşılabilirlik. Bir düşüncenin sunulmasındaki en temel ilke olan anlaşılabilirlik ifade kültürüne ait her şey için olduğu gibi müzik için de geçerlidir. Webern müzikte anlaşılabilirliğin gerçekleşmesini diğer diyalektik bir ilke olan bütünlüğe bağlayarak, anlam yaratabilmek için bütünlüğün zorunlu bir şey olduğunu söylemektedir. "Çok genel olarak bütünlük, bir şeyin tüm bileşenleri arasında mümkün olan en fazla ilişkiyi kurmaktır. O halde müzikte de, insanın dile getirdiği her şey de olduğu gibi amaç bütünlüğü oluşturan parçalar arasındaki ilişkileri mümkün olduğunca açık hale getirmektir" (Webern, 1998: 60).

\section{6. ÜSLUP}

Küçük bir müziksel fikirden yola çıkarak ses ve zamanın çok çeşitli estetik yordamlara göre düzenlenip işlenmesini içeren kompozisyon, en genel anlamda bestecinin kavramlarını düzenleyip sanatının dilini kendine özgü bir yapıda konuşturmasıyla üs/up'una kavuşmuş olur. Dilimizde karşılığı deyiş olarak belirlenen üslup, bir kompozisyonun teknik bakımdan ortaya çıktıktan sonra, yaratıcının kişiliğine göre eserin özgün olup olmamasını sağlayan şeydir. Bu noktada bir örnekleme yapmak gerekirse klasik dönemin iki büyük bestecisi Mozart ve Haydn'ı karşılaştırabiliriz. Klasik dönemin stilistik benzerlikleri içinde Mozart ve Haydn'ın müziğini birbirinden ayıran en temel özellik aralarındaki üslup farklılığıdır. Bu iki bestecinin kendine has üslupları-deyişleri sayesinde dinlediğimiz müziğin kime ait olduğu anlaşılır. Dolayısıyla üslupun bir kompozisyonun sanatsal ifadeye dönüşmesinde en temel unsurlardan biri olduğu söylenebilir.

Bu bağlamda "kompozisyonda yaratıcılık iki açıdan ele alınabilir. İlki, melodi, armoni, form, orkestrasyon ve benzer öğelerde yenilik; ikincisi, üst düzey bir sanatçılı̆a bağlı olarak güçlü kişilik ifadesi" (Say, 1984: 734). 15. Yüzyılda müziğe yeni kontrpuan değerleri getirenler, 18. yüzyılın ortalarında sonat formunu geliştirenler, 20. yüzyılın başında tonal sisteme alternatif olarak atonaliteyi geliştirenler vb. ilk kategoriye girer. Güçlü bir kişilik ifadesine örnek bulmak ise çok daha kolaydır. Döneminde birçok formu doruğuna ulaştıran, armoni ve polifoni dehası J. S. Bach, özellikle klasik dönemde sonat formunu işleyerek formu şekillendiren Haydn, Mozart, Beethoven vb.. romantik dönemin özgün bestecisi Chopin, Schumann batı sanat müziği tarihinde özgün ve güçlü sanatsal kişilik örneğine verilecek onlarca besteciden ilk akla gelenlerdir. Kompozisyonda yenilik ve güçlü kişilik ifadesi aslında birbiriyle bağlantılıdır da denebilir. Batı sanat müziğinin 300 yıllık geçmişine bakılırsa hemen hemen tarihe geçmiş bütün bestecilerin şu ya da bu biçimde bu iki özelliği taşıdığını görebiliriz.

\section{SONUÇ}


Bütün bu yukarıda ele aldığımız noktalardan sonra genel bir tanıma ulaşmayı deneyebiliriz. Avrupa sanat müziğinde beste en genel anlamda ritm, ezgi, armoni ve biçim birliğinden doğan yeni arayışları ifade eder. Besteciler hemen her dönemde, gerek yeni bir armonik dil oluşturmak, gerekse kişilikli bir ezgisel ya da ritmik anlayışa ulaşmak için yarattıkları müzikal fikirlerin koordinasyonunu ve bütünlüğü sağlamaya çalışmışlardır. Besteleme süreci her bir notanın, her bir ritmik yapının, her armonik-polifonik bağlantının ya da her bir melodik yapının müzik sanatına özgü yöntem ve tekniklerle, çeşitli estetik yordamlara göre işlenmesini içerir. Besteci kompozisyonunda belirli bir üslup ve biçim dengesi gözeterek, gerek dönemin müziksel dilinin gerek kendi getirdiği yeniliklerin uzantısında çokluğa dayalı bir birlik oluşturmayı, anlaşılabilir bir bütünselliğe ulaşmayı amaçlar.

Beste ve bestecilik kavramı, geleneksel ve popüler müzik üretiminde farklı anlamlara sahiptir. Bu farklar özellikle müziğin üretimi aşamasında belirginleşir. Simon Frith'e göre "sanat müziği, aşkın bir deneyimin şart koşulduğu bir çerçevede işler ve bunu genelde eğitimliler tecrübe edebilirler. Halk müziği, bir topluluk ya da toplumun otantik deneyimi ile bağlantılı düşünülür. Popüler müzik ise, müzik endüstrisi içinde oluşturulur ve endüstrinin aktörleri tarafından yaratılır" (akt. Erol, 2009: 208).

Kaemmer (1993) müzik incelemesinde sınıflandırmanın çoğu kez, bir toplumda ortaya çıkan müziksel yaratılar ya da seslendirmelerin çeşitleri anlamına gelen tür çerçevesinde ifade edildiğini söylemektedir. Türler ise birbirinden en çok şu üç ölçüte göre ayrılır. Müziğin kullanılış şekli (ninni, savaş şarkıları, ritüel şarkıları), seslendirme şekilleri (solo, koro, ezgisel okuma) ve kullanılan çalgılar (yaylı, üflemeli, vurmalı vb). Dolayısıyla bu noktada, beste ve bestecilik kavramlarının bu üç ölçüte göre kıyaslanabilir özelliklere sahip olduğu söylenebilir.

Batı sanat müziği özellikle orta çağ boyunca dini amaçlar için kullanılmıştır. Yeni arayışlar teknoloji ve bilimin gelişmesi, müziği ve besteciliği sürekli etkilemiş, yaşanan toplumsal değişimlerle birlikte müzik dünyasal alanla ilgili konulara yönelmiştir. Müziğin üretiminde sürekli bir sistemleştirme çabası görülür. Müzikle ilgili her olgu çağlar boyunca edimsel ve söylemsel bilinç ışı̆ıında sorgulanmıştır. Dolayısıyla sanat müziği her yönüyle sürekli bir gelişim içinde olmuştur.

Günümüzde kitle medyası hemen her tür müziğin yayınını yapmaktadır. Ancak batı sanat müziğinin asıl seslendirildiği yer konser salonlarıdır. Bestecinin ürünü salonlarda profesyonel müzisyenler tarafından seslendirilir, dinleyici karşısına çıkar. Amaç daha çok sanatsal nitelik ve sanatsal hazla ilişkilidir. Müzik, bestecisinin amacına bağlı olarak solo, koro, orkestral gibi çeşitli seslendirme imkanlarına sahiptir. Bestecinin kullandığı çalgılar ağırlıklı olarak Avrupa kültürünün çalgılarıdır. Gerçi günümüzde besteciler ister etnik kökenli bir çalgı olsun, ister elektronik ortamda üretilmiş sesler olsun bestelerinde elbette istedikleri çalgı ya da sesi kullanabilme özgürlüğüne sahiptirler. Ancak yine de batı sanat müziğinde kullanılan çalgıların, özellikle ses sistemine bağlı olarak olarak bu kültürün kendi ürettiği çalgılar olduğu söylenebilir.

Geleneksel topluluk ve toplumların müziği kullanımı ise birbirinden farklılıklar gösterir. Bu noktada ancak benzerlikler üzerinden genellemeler yapılabilir. Çünkü bir toplum ya da toplulukta din için kullanılan müzik, diğer bir toplulukta dans, oyun ya da geçiş ayini gibi ritüellerde, bir ya da daha çok amaç için kullanılıyor olabilir. Geleneksel ya da halk müziği için söylenebilecek ilk şey, her ne kadar başlangıçta bir yaratanı olsa da bu tür tarihsel süreçten geçerek anonimleşir-varlığına kavuşur. Oluşum süreci toplumsal sistemdeki ihtiyaçlarla ilişkilendiğinden üretimi ve tüketimi zaman içinde doğal bir yaygınlık kazanır. Müziği ilk besteleyen genellikle belirli değildir ve müzik kullanıldığı alanlara göre adlandırılabilir. (Av müziği, hasat şarkısı vb.) Seslendirme şekilleri solo, koro ya da ezgisel olabilir. Ender olarak bazı topluluk ve toplumlarda basit çok seslilik diyebileceğimiz yapılar da bulunmaktadır. Çalgılar, toplumların metalurji ya da ağaç kullanma yetilerine göre otantik özellikler gösterir. Müzikteki tını ideali toplumun yaşayış şekillerine, inançlarına, gelenek - göreneklerine bağlı olarak kültür içinde gömülüdür ve kuşaktan kuşağa usta çırak iletişimiyle aktarılır.

Popüler müziğin üretim süreci ise daha komplekstir. Manuel'e göre popüler müzik öteki müzik türlerinden iki ana özelliğiyle ayırt edilebilir. İlki, popüler müzik geniş ölçüde kitle medyası tarafından yaygınlaştırılır; ikinci olarak popüler müzik pazarlama şirketleri için temel olan bir kitle ürünüdür (Erol, 2002). Günümüz koşullarında hemen her müzik türünün çeşitli 
manipülasyonlarla popülerleştirilmesi mümkünse de, popüler müzik üretiminde beste çok boyutlu bir anlama sahiptir. Yani müzik üretim sürecinde ilk bestecisinden aranjörüne, tonmaysterinden yapımcısına kadar birçok değişikliğe uğrar. Bu yeniden üretim aşaması pazarlama şirketleri tarafından kitle esasına göre düzenlenir. Geleneksel ve sanat müziğinden ayrılan önemli bir özelliği müziğin çoğunlukla eğlence aracı olarak kullanılması gösterilebilir. Ev, iş yeri ya da kafe gibi kamu alanı özelliği taşıyan birçok ortamda seslendirilebilir. Kayıt teknolojisi ve elektronik müzik sistemleri, ses üretimi ve kullanımında başat unsurlardır. Besteci/besteciler ürettikleri müzikte istedikleri çalgıyı ve sesi (akustik - elektronik), bilinen bilinmeyen her türlü sound'u elde etmek için kullanabilir. Sanat ya da geleneksel müzikte ürün çıktığı kültürel yapının izlerini taşırken ideolojik-politik olabilir. Gerçi popüler müzikte de aynı durum söz konusudur ancak, besteleme edimi genellikle uğradığı manipülasyonlarla daha etkili bir yönlendirmeye tabi olur. Dolayısıyla bu süreç ağırlıklı olarak müzik endüstrisinin hakimiyeti altında gelişir.

\section{KAYNAKÇA}

Apel, W., (1951). Harvard Dictionary of Music. England, Routledge \& Kegan Paul Itd.

Çalışlar, A., (1991). Milliyet Sanat Ansiklopedisi. Milliyet Basım Yayın.

Erol, A., (2002). Popüler Müziği Anlamak-Kültürel Kimlik Bağlamında Popüler Müzikte Anlam. İstanbul, Bağlam Yayıncılık.

Erol, A., (2009). Müzik Üzerine Düşünmek. İstanbul, Bağlam Yayıncılık.

Erdal, B., (2003). "Barok Dönemdeki Türler ve Biçimlerin Biçim Bilgisi İçindeki Yeri ve Biçim Bilgisi Dersinin Gerekliliği". İzmir, Yayınlanmamış Yüksek Lisans Tezi.

Eisler, H., (2006). Müzik Üzerine Tartışmalar. İstanbul, Derleme, Çev. Yılmaz Onay, Evrensel Basım Yayın.

Fırat, E.O., (1999). Çağdaş Küğ Tarihi İçin İmler I. İstanbul, Yapı Kredi Kültür Sanat Yayıncilık.

Hodeir, A., (1971). Müzikte Türler ve Biçimler. İstanbul, Çev. Usmanbaş, İ. M. E. Basımevi.

Kaemmer, J. E., (1993). Music in Human Life, Anthropological Perspectives on Music. Austin University of Texas, Çev. Yetkin Ozer ( yayınlanmadı).

Stravinsky, I., (1942). Altı Derste Müziğin Poetikası. İstanbul, Harvard College, Çev. Ali Bucak, Pan Yayınları.

Say, A., (1984). Müzik Ansiklopedisi Cilt 3. Ankara, Başkent Yayınevi.

Say, A., (1995). Müzik Tarihi. Ankara, Müzik Ansiklopedisi Yayınları.

Say, A., (2005). Müzik Sözlüğü. Ankara, Müzik Ansiklopedisi Yayınları.

Webern, A., (1998).Yeni Müziğe Doğru. İstanbul, Pan Yayıncılık.

Yavaşça, A., (2002). Türk Musikisi'nde Kompozisyon ve Beste Biçimleri. İstanbul, Mart Matbaacilık.

http://www.grovemusic.com. (son giriş: 13.04.2012).

\section{EXTENDED ABSTRACT}

If one of the most fundamental dimensions for the formation of music is the execution, it can be said that creation is another and more important dimension. Today in different cultures, 
it is known that music has a wide variety of production styles which can be changeable by the nature of the cultural structure. Apart from many other cultures (not superior) that exist on Earth, the European civilization's sound system, which was based on Ancient Greece, had evolved over the centuries and had achieved a systematic unity. As a result of these developments, the concepts of composition and composer in western art music first appeared between the 15th and 16th centuries. Many sources, which have been translated into Turkish or published in Turkish, have not included the act of composing, except for a few glossary articles it. Therefore, this study, which included the thoughts of the famous composer Starvinsky on the act of composition, aims to meet this need within a certain framework. At the end of discussion of related literature the difference between the ways in which Western art music and traditional and popular music were created was delineated.

Composition in European art music expresses the most general quest for rhythm, melody, harmony and unity of form. In almost every period, composers have tried to ensure the coordination and integrity of the musical ideas they create in order to create a new harmonic language and reach a melody or rhythmic understanding with personality. The composition process involves the processing of each note, each rhythmic structure, each harmonicpolyphonic connection, or each melodic structure according to various aesthetic procedures, using methods and techniques specific to the art of music. The composer aims to create a unity based on multiplicity in the extension of the musical language of the period and the innovations brought by him, and to reach a comprehensible integrity by considering a certain balance of style and form in his composition.

The concept of composition and composer has different meanings in traditional and popular music production. These differences are particularly evident in the production stage of music. According to Simon Frith, "art music operates within the framework of a transcendental experience, and educated people can usually experience it. Folk music is thought to be linked to the authentic experience of a community or society. Popular music is created within the music industry and is created by the actors of the industry" (cited in Erol, 2009: 208).

Western art music was used for religious purposes especially during the Middle Ages. New searches have continuously influenced the development of technology and science, music and composer, and with the social changes, music has been directed to issues related to the earthly field. There is a continuous systematization effort in the production of music. Every phenomenon about music has been questioned in the light of actual and discursive consciousness throughout the ages. Therefore, art music has been in a continuous development in every aspect.

Today, mass media broadcasts almost all kinds of music. However, the main venue of western art music is concert halls. The composer's product is performed by professional musicians in the halls and meets the audience. The aim is more related to artistic quality and artistic pleasure. Music, depending on the purpose of the composer, solo, choir, orchestral, such as has a variety of voice. The instruments used by the composer are mainly instruments of European culture. Today, composers, of course, have the freedom to use any instrument or sound they want, whether they are an ethnic instrument or electronic sounds. However, it can be said that the instruments used in western art music are produced by this culture, especially depending on the sound system.

The use of music by traditional communities and societies differs from one another. At this point, generalizations can be made only through similarities. Because music used for religion in one community or society may be used for one or more purposes in rituals such as dance, play or ritual in another community. The first thing that can be said for traditional or folk music is that it becomes anonymized-through its historical process, even though it was originally a creator. Since the formation process is related to the needs in the social system, its production and consumption gain a natural prevalence over time. The first composer of music is often unclear and can be named according to the fields in which it is used. (Hunting music, harvest song, etc.) Voice forms can be solo, choir or melody. Rarely, in some communities and societies there are structures that we can call simple polyphony. The instruments show authentic features according to the societies' ability to use metallurgy or wood. The ideal of timbre in music is embedded in the culture depending on the way of 
living, beliefs, traditions and traditions of the society and transferred from generation to generation with skillful apprentice communication.

The production process of popular music is more complex. According to Manuel, popular music can be distinguished from other genres by two main characteristics. First, popular music is widely disseminated by the mass media; secondly, it is a mass product that is the basis for popular music marketing companies (Erol, 2002). Although it is possible to popularize almost every kind of music with various manipulations under present conditions, composition has a multidimensional meaning in popular music production. In other words, during the music production process, it undergoes many changes from its first composer to arranger, tonmayster and producer. This reproduction stage is regulated by the marketing companies on a mass basis. An important feature that distinguishes itself from traditional and art music is that music is mostly used as a means of entertainment. It can be performed in many public spaces, such as homes, offices or cafes. Recording technology and electronic music systems are the dominant elements in sound production and use. The composer (s) can use the desired instrument and sound (acoustic - electronic) in the music they produce to obtain any unknown sound. In art or traditional music, the product may be ideologicalpolitical while carrying the traces of the cultural structure in which it is produced. Although this is the case in popular music, the act of composing is often subject to more effective manipulation through manipulations. Therefore, this process develops mainly under the dominance of the music industry. 